\title{
Cancer in thyroid nodules with fine-needle aspiration in Korean pediatric populations
}

Joon Ho Jang, MD', So Hyun Park, MD', Kyung soon Cho, MD', Won Kyung Cho, MD', Young Jin Suh, MD ${ }^{4}$, Byung Kyu Suh, MD ${ }^{5}$, Dae Kyun Koh, MD'

'Department of Pediatrics, St. Vincent's Hospital, The Catholic University of Korea, ${ }^{2}$ Central Children's Hospital, Hwasung, ${ }^{3}$ Department of Pediatrics, Bucheon St. Mary's Hospital, The Catholic University of Korea, Bucheon, ${ }^{4}$ Department of Surgery, St. Vincent's Hospital, The Catholic University of Korea, Suwon, ${ }^{5}$ Department of Pediatrics, Seoul St. Mary's Hospital, The Catholic University of Korea, Seoul, Korea

Received: 23 October, 2017 Revised: 12 December, 2017 Accepted: 15 December, 2017

Address for correspondence: So Hyun Park, MD

Central Children's Hospital, 17 Dongtan-jisung-ro, Hwasung 18454, Korea

Tel: +82-31-249-8220

Fax: +82-31-8060-5044

E-mail: nicedoct@gmail.com

https://orcid.org/0000-0002-52834619
Purpose: To determine the prevalence and clinical findings of benign thyroid nodules and cancer in Korean pediatric patients with thyroid nodules.

Methods: We investigated the medical records of 134 patients aged younger than 18 years who had a goiter, thyroid nodule, thyroid mass, or thyroid cancer who underwent fine needle aspiration biopsy (FNAB).

Results: The study population included 113 females (84.3\%) and 21 males (13.7\%); the mean patient age was $16.1 \pm 2.3$ years (range, $8-18$ years). Of the 134 patients, $24(18.0 \%)$ were finally diagnosed with thyroid cancer, of which $20(83.3 \%)$ were papillary cancer and $4(16.7 \%)$ were follicular cancer. No patient was exposed to radiation. FNAB revealed malignant cancer in 21 of the patients; 3 were initially reported as having benign tumors by FNAB, but were later diagnosed with follicular cancer. An additional 13 patients were suspected to have malignant tumors by FNAB, with a final diagnosis of nodular hyperplasia. Cystic nodules were more common in the benign group. The percentages of cervical lymphadenopathy and irregular nodular margins were higher in the malignant group compared to the benign group. Cervical lymphadenopathy and FNAB malignant findings were highly suggestive of malignant nodules.

Conclusion: Thyroid cancer prevalence in a Korean pediatric population is comparable to reported estimates of worldwide thyroid cancer prevalence. In this population, cancer predominates on the right thyroid lobe. Papillary thyroid cancers are dominant in the Korean pediatric population but are less prevalent than in Korean adults. As expected, FNAB was highly accurate in predicting malignant nodules.

Keywords: Pediatric, Thyroid nodule, Thyroid cancer

\section{Introduction}

The incidence of thyroid malignancy has been increasing in adults, most rapidly in Korea. ${ }^{1)}$ Currently, thyroid cancer is the most common cancer in young adults and adolescents in Korea. ${ }^{2)}$ Many factors have been suggested to contribute to this rise in incidence. While environmental and genetic factors can affect the incidence of thyroid cancer, improved detection via advanced imaging techniques is regarded as the main factor responsible for the rise in incidence of small thyroid cancers. ${ }^{3,4)}$ Ahn et al. ${ }^{1)}$ suggested that thyroid cancer screening has increased detection of papillary thyroid cancers in Korea. Since thyroid screening in Korea is conducted in individuals older than 20 years, the factors contributing to the rise of thyroid cancer incidence in adolescents are unknown.

Thyroid nodules are infrequent in pediatric populations, occurring in only $0.2 \%-5 \%$ of these individuals. ${ }^{5-7)}$ However, compared with adults, thyroid nodules are more often malignant in pediatric populations (up to $26 \%$ of all nodules). Moreover, the incidence of thyroid cancer in the pediatric population seems to be increasing. ${ }^{8-10)}$ 
Few reports have investigated thyroid nodules and cancer in pediatric populations. Moreover, reports about the incidence of thyroid cancer in pediatric patients with thyroid nodules in Korea are rare. ${ }^{11-13)}$ In this study, we aimed to determine the prevalence and clinical findings of thyroid cancer in thyroid nodules and to compare malignant and benign nodules in a Korean pediatric population.

\section{Materials and methods}

\section{Subjects and methods}

We investigated the medical records of 905 patients aged less than 18 years who had a goiter, thyroid nodule, thyroid mass, or thyroid cancer and who had visited St. Vincent's Hospital or Bucheon St. Mary's Hospital between January 2006 and December 2015. One hundred sixteen patients were excluded due to incomplete medical records, and another 617 were excluded because they had a diffuse goiter without a nodule. Of the remaining patients, 38 had not undergone ultrasonographyguided-fine needle aspiration biopsy (FNAB); therefore, 134 patients were included in the present analysis (Fig. 1).

FNAB was not performed for some patients (38 patients who were excluded) due to the following reasons: cystic nodule $(n=8)$, small nodule $(<1 \mathrm{~cm})$ with little change in size during more than 1 year of follow-up $(n=6)$, small single nodule with benign nature in ultrasonography (US) findings $(n=8)$, initial operation without FNAB due to large size $(n=3)$, or no description about the reasons and follow-up duration less than 1 year $(n=13)$. Lobectomy was performed for 3 of the patients who did not undergo FNAB because of large tumor size. The final diagnosis was nodular goiter in all 3 patients. Of the 38 patients, none had a cancer diagnosis in their medical records.

US and FNAB were performed by well-trained radiologists, and FNAB specimens were reviewed by qualified pathologists. We regarded positive FNAB findings as more than atypia of undetermined significance or a follicular lesion of undetermined significance. ${ }^{14)}$

Serum triiodothyronine (T3), free T4 (fT4), and thyroid stimulating hormone (TSH) levels were measured by a chemiluminescent microparticle immunoassay using an Architect 12000 analyzer (Abbott, Abbott Park, IL, USA). Serum anti-thyroid peroxidase antibody (TPO Ab) and antithyroglobulin antibody ( $\mathrm{Tg} \mathrm{Ab}$ ) levels were measured by a chemiluminescent immunometric assay using an Immulite 200 analyzer (Siemens Healthcare Diagnostic Products Ltd., Llanberis, Gwynedd, UK). TSHR Ab level, considered to reflect thyrotropin binding inhibitory immunoglobulin level, were measured by an electrochemiluminescence immunoassay using a Cobase 411 analyzer (Roche Diagnostics GmbH, Mannheim, Germany). The reference values were as follows: T3, 0.58-1.9 ng/mL; fT4, 0.7-1.79 ng/dL; TSH, 0.35-4.95 $\mu \mathrm{IU} / \mathrm{mL}$; TPO Ab, $<30 \mathrm{IU} / \mathrm{mL} ; \mathrm{Tg} \mathrm{Ab},<40 \mathrm{IU} / \mathrm{mL}$; and TSHR Ab, <1.75 IU/L.

This retrospective study did not require written informed consent, and all of the work in this study was approved by the Institutional Review Boards of St. Vincent's Hospital (VC14risi0059) and Bucheon St. Mary's Hospital (HC17RESI0073).

\section{Statistical analysis}

Statistical analyses were performed using IBM SPSS Statistics ver. 21.0 (IBM Co., Armonk, NY, USA). Continuous variables are expressed as mean \pm standard deviation. Continuous data were analyzed using Student $t$-test and Mann-Whitney $U$-test, whereas categorical variables were analyzed using the chisquare test or Fisher exact test. Logistic regression analysis was performed to identify the risk factors contributing to malignancy in patients with thyroid nodule. $P$-values of $<0.05$ were considered statistically significant.

\section{Results}

The study population included 113 female patients (84.3\%) and 21 male patients (13.7\%); the mean patient age was $16.1 \pm 2.3$ (8-18) years. Thyroidectomy was performed in 36 patients, and total thyroidectomy was performed in 15 of the patients with cancer. Of the 134 patients, 24 (18.0\%) were finally diagnosed with thyroid cancer, $20(83.3 \%)$ of which were papillary cancer (PTC) and 4 (16.7\%) of which were follicular cancer.

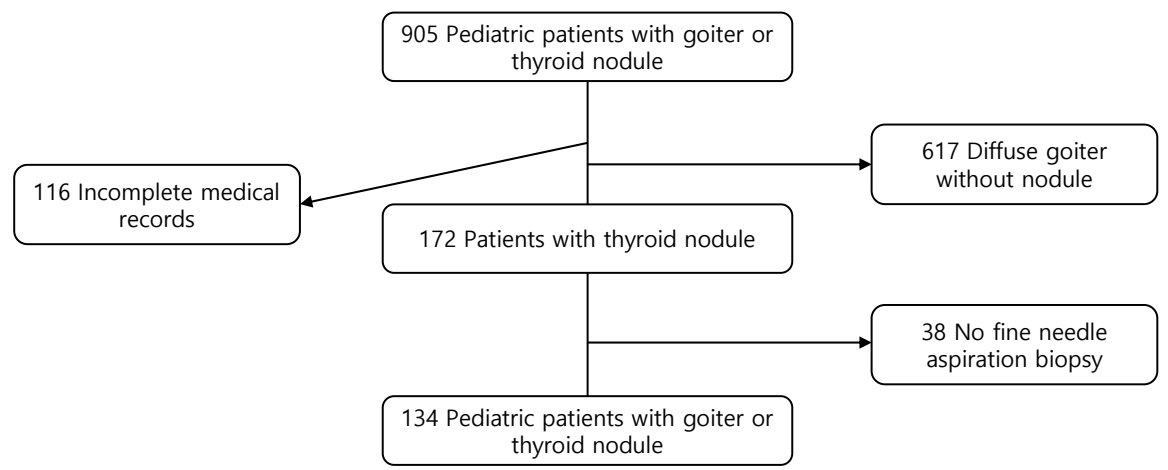

Fig. 1. Flow chart of the study population with thyroid nodule. 
No patient was exposed to radiation. FNAB initially revealed that the nodule was positive (more than atypia) in 34 patients of the 134 and gave positive results in 21 of the patients with pathological cancer. While 3 of the 24 nodules in patients with cancer were initially reported as benign on FNAB, they were eventually diagnosed as follicular cancer. One of the patients had a 3.5-cm solid mass with irregular margins and cervical lymphadenopathy. However, another patient had a mass less than $1 \mathrm{~cm}$ in diameter and no calcification with multiple masses (more than 3 pieces) less than $1 \mathrm{~cm}$. The third patient had a rapidly growing large mass with cervical lymphadenopathy. Otherwise, 13 of the patients who showed initially positive FNAB were finally diagnosed with nodular hyperplasia.

We next compared clinical parameters in the 2 groups (malignant vs. benign). Thyroid function, nodule size, and nodule number were not different between the 2 groups. However, cystic nodules were more common in the benign group (Table 1) $(P<0.001)$. Cervical lymphadenopathy and irregular nodular margins were also more common in the malignant group compared to the benign group (Table 1). Although some FNAB findings were discordant with the final diagnosis, $85.1 \%$ of the FNAB findings were concordant with the final diagnosis.

In regression analysis, cervical lymphadenopathy (odds ratio $[\mathrm{OR}], 5.417$; 95\% confidence interval [CI], 1.140-25.747;

Table 1. Comparison of the features of malignant and benign nodules $(n=124)$

\begin{tabular}{|c|c|c|c|}
\hline Variable & Benign & Malignancy & $P$-value \\
\hline No. of patients & $110(82.0)$ & $24(18.0)$ & \\
\hline Sex & & & 0.394 \\
\hline Female & $91(82.7)$ & $22(91.7)$ & \\
\hline Male & $19(17.3)$ & $2(8.3)$ & \\
\hline Age (yr) & $16.1 \pm 3.1$ & $16.1 \pm 2.2$ & 0.972 \\
\hline fT4 (ng/dL) & $1.3 \pm 0.3$ & $1.2 \pm 0.5$ & 0.539 \\
\hline $\mathrm{T} 3$ (ng/mL) & $1.5 \pm 0.8$ & $1.2 \pm 0.4$ & 0.096 \\
\hline TSH ( $\mu \mathrm{IU} / \mathrm{mL})$ & $1.8 \pm 1.5$ & $3.4 \pm 1.4$ & 0.923 \\
\hline Nodule size (cm) & $2.1 \pm 1.2$ & $2.2 \pm 1.3$ & 0.682 \\
\hline Number of nodule & $1.3 \pm 0.6$ & $1.8 \pm 0.4$ & 0.892 \\
\hline Cervical lymphadenopathy & $17(15.5)$ & $11(45.8)$ & 0.006 \\
\hline \multicolumn{4}{|l|}{ Characteristics of nodule } \\
\hline Hypoechoic solid & $80(72.7)$ & $23(99)$ & 0.064 \\
\hline Irregular margin & $4(3.6)$ & $6(25)$ & 0.002 \\
\hline Cystic & $39(35.5)$ & $0(0)$ & $<0.001$ \\
\hline Calcification & $11(10.0)$ & $5(20.8)$ & 0.098 \\
\hline Location & & & 0.089 \\
\hline Left lobe & $44(40.0)$ & $4(16.7)$ & \\
\hline Right lobe & $56(50.9)$ & $17(70.8)$ & \\
\hline Both or isthmus & $10(9.1)$ & $3(12.5)$ & \\
\hline FNAB finding & & & $<0.001$ \\
\hline Negative & 97 (88.2) & $3(12.5)$ & \\
\hline Positive & $13(11.8)$ & $21(87.5)$ & \\
\hline
\end{tabular}

Values are presented as number (\%) or mean \pm standard deviation. fT4, free $T 4 ; T 3$, triiodothyronine; TSH, thyroid stimulating hormone; FNAB, fine needle aspiration biopsy.
$P=0.034$ ) (Table 2) and FNAB malignant findings were highly suggestive of malignant nodules (OR, 50.377; 95\% CI, 9.072279.755; $P<0.001)$ (Table 2).

\section{Discussion}

In the present study, the incidence of thyroid cancer in Korean pediatric patients with thyroid nodules was $18 \%$. This incidence is comparable to the reported worldwide prevalence of thyroid cancer in pediatric thyroid nodules of $20 \%-26 \%$. ${ }^{8,9)}$ Including patients who did not undergo FNAB, and assuming that these patients might have benign nodules, 24 of the 172 thyroid nodules $(14 \%)$ were malignant in pediatric patients in the present study. This incidence is slightly lower than those reported for other countries. In Korea, the childhood thyroid cancer incidence increased 3 fold from 1999 to 2012 $(0.5 / 100,000$ to $1.7 / 100,000)$, based on Korea Central Cancer Registry. ${ }^{13)}$ In the United States and the United Kingdom, the incidence of thyroid cancer in pediatric populations also appears to be increasing. ${ }^{10,13)}$ Additionally, the proportion of thyroid cancer out of all childhood cancers increased from $4.4 \%$ in 1999 to $10.6 \%$ in $2012 .{ }^{13)}$ Little is known about the factors responsible for this increasing incidence of thyroid cancer in pediatric populations, due to the low incidence of thyroid cancer. ${ }^{15)}$ One risk factor is prior radiation exposure, e.g., in patients whose primary malignancy was treated with radiation. ${ }^{16)}$ PTC is related to radiation exposure. ${ }^{17,18)}$ However, none of the patients in the present study had a history of radiation exposure. In adult patients in Korea, cancer screening tests might contribute to the increasing incidence of thyroid cancer. However, children do not undergo these screening tests. According to a recent study, the proportion of PTC has decreased in Korean pediatric patients with thyroid cancer. ${ }^{12)}$ Therefore, environmental or genetic factors might be risk factors of pediatric thyroid cancer. ${ }^{19-21)}$

Similar to other studies, PTC was the major cancer in the present study. PTC accounts for more than $90 \%$ of all childhood thyroid cancers. ${ }^{22-24)}$ In another study of pediatric thyroid cancer in Korea, the incidence of PTC was 93.3\%. ${ }^{12)}$ PTC frequently presents as a thyroid nodule with cervical lymphadenopathy. ${ }^{12,22}$ Lymphadenopathy and margin invasion are characteristics of malignant nodules, and the presence of these 2 findings was more frequent in cancer nodules than in benign nodules in our study.

In this study, FNAB findings were used to discriminate

Table 2. Predictors of malignancy in patients with thyroid nodule at logistic regression analysis

\begin{tabular}{lcr}
\hline Predictor & OR $(95 \% \mathrm{Cl})$ & $P$-value \\
\hline Cervical lymphadenopathy & $5.417(1.140-25.747)$ & 0.034 \\
Cystic nodule & $0.154(0.023-1.044)$ & 0.055 \\
Irregular margin & $4.909(0.888-27.129)$ & 0.068 \\
FNAB positive & $50.377(9.072-279.755)$ & $<0.001$ \\
\hline
\end{tabular}

$\mathrm{OR}$, odds ratio; $\mathrm{Cl}$, confidence interval; $\mathrm{FNAB}$, fine needle aspiration biopsy. 
between benign and malignant nodules in pediatric thyroid cancer. The diagnostic performance of FNAB was similar to that of other studies, which have reported a sensitivity of $83 \%-98 \%$ and a specificity of $70 \%-92 \%{ }^{5,25)}$ The sensitivity of FNAB in our study was $87.5 \%$ and the specificity was $88.2 \%$, which are comparable to other results. FNAB is the most reliable method for determining whether thyroid nodules are malignant or benign.

Our study raises the question of how FNAB can be used to optimally evaluate children with thyroid nodules. According to the 2015 American Thyroid Association guidelines, FNAB is not warranted for a nodule $<1 \mathrm{~cm}$ when the patient does not have a history of radiation exposure or pathologic regional lymphadenopathy. ${ }^{26)}$ However, the size criterion is problematic in children because thyroid volume varies by age. ${ }^{27)}$ Therefore, US characteristics and clinical findings should be used to determine whether FNAB should be conducted. ${ }^{28)}$ Irregular margins, hypoechogenicity, abnormal cervical lymph nodes, and increased intranodular blood flow are more common in malignant nodules. ${ }^{27,29)}$ Of these findings, cervical lymphadenopathy and irregular margins were found to be more common in malignant nodules than benign nodules in the present study. We could not compare intranodular blood flow between the groups, since this parameter is rarely described in medical records. Pediatric guidelines recommend that US characteristics and clinical findings should be emphasized rather than nodular size alone. ${ }^{28)}$

Other reports have suggested that high TSH level is related to thyroid cancer in patients with thyroid nodules. Therefore, TSH suppression could be useful for evaluating thyroid nodules, as stated in some of the pediatric guidelines. ${ }^{28,30)}$ However, we did not observe any differences in TSH level between benign and malignant nodules in the present study.

On account of limited medical records, we could identify only 6 patients had family history of thyroid disease (one patient had grandmother with thyroid cancer, and the others were only described as thyroid disease family history) in the cancer group.

A limitation of the present study is that it included a retrospective review of medical records. Although patients from 2 different hospitals were included, the relatively small study population hindered the identification of significant differences in our analyses. Despite these limitations, this study reports the prevalence of malignancy in pediatric thyroid nodules and identifies clues for discriminating benign from malignant thyroid nodules in Korean pediatric populations.

In conclusion, the incidence of thyroid cancer in a Korean pediatric population was comparable to the reported worldwide incidence in pediatric populations with thyroid nodules. Papillary thyroid cancers are dominant in Korean pediatric populations but are less prevalent than in Korean adults. Cervical lymphadenopathy increases the risk of malignancy; as expected, FNAB was highly accurate in predicting malignant nodules.

\section{Conflict of interest}

No potential conflict of interest relevant to this article was reported.

\section{References}

1. Ahn HS, Kim HJ, Kim KH, Lee YS, Han SJ, Kim Y, et al. Thyroid cancer screening in South Korea increases detection of papillary cancers with no impact on other subtypes or thyroid cancer mortality. Thyroi. 2016;26:153540.

2. Jung KW, Park S, Kong HJ, Won YJ, Lee JY, Park EC, et al. Cancer statistics in Korea: incidence, mortality, survival, and prevalence in 2008. Cancer Res Treat 2011;43:1-11.

3. Pandeya N, McLeod DS, Balasubramaniam K, Baade PD, Youl PH, Bain CJ, et al. Increasing thyroid cancer incidence in Queensland, Australia 1982-2008 - true increase or overdiagnosis? Clin Endocrinol (Oxf) 2015 Jan 19 [Epub]. https://doi.org/10.1111/cen.12724.

4. Davies L, Welch HG. Increasing incidence of thyroid cancer in the United States, 1973-2002. JAMA 2006;295:2164-7.

5. American Thyroid Association (ATA) Guidelines Taskforce on Thyroid Nodules and Differentiated Thyroid Cancer, Cooper DS, Doherty GM, Haugen BR, Kloos RT, Lee SL, et al. Revised American Thyroid Association management guidelines for patients with thyroid nodules and differentiated thyroid cancer. Thyroid 2009;19:1167-214.

6. The NCCN Clinical Practice Guidelines in Oncology, Thyroid Carcinoma (Version 2, 2013). Fort Wathington (PA): National Comprehensive Cancer Network; c2017 [cited 2013 Oct 3] Available from: http://www.nccn.org/ professionals/physician_gls/f_guidelines.asp\#site.

7. British Thyroid Association, Royal College of Physicians. Guidelines for the management of thyroid cancer (Perros P, ed) 2nd ed. Report of the Thyroid Cancer Guidelines Update Group. London: Royal College of Physicians, 2007.

8. Mussa A, De Andrea M, Motta M, Mormile A, Palestini $\mathrm{N}$, Corrias A. Predictors of malignancy in children with thyroid nodules. J Pediatr 2015;167:886-92.

9. Guille JT, Opoku-Boateng A, Thibeault SL, Chen H. Evaluation and management of the pediatric thyroid nodule. Oncologist 2015;20:19-27.

10. Vergamini LB, Frazier AL, Abrantes FL, Ribeiro KB, Rodriguez-Galindo C. Increase in the incidence of differentiated thyroid carcinoma in children, adolescents, and young adults: a population-based study. J Pediatr 2014;164:1481-5.

11. Lee SJ, Lim GY, Kim JY, Chung MH. Diagnostic performance of thyroid ultrasonography screening in pediatric patients with a hypothyroid, hyperthyroid or euthyroid goiter. Pediatr Radiol 2016;46:104-11.

12. Lee YA, Jung HW, Kim HY, Choi H, Kim HY, Hah JH, et al. Pediatric patients with multifocal papillary thyroid 
cancer have higher recurrence rates than adult patients: a retrospective analysis of a large pediatric thyroid cancer cohort over 33 years. J Clin Endocrinol Metab 2015; 100:1619-29.

13. Cho YY, Jang HW, Joung JY, Park SM, Jeong DJ, Kim SW, et al. Trends in thyroid cancer incidence in Korean children (1999-2012) based on palpation and nonpalpation detection methods. Eur Thyroid J 2015;4:252-9.

14. Norlén O, Charlton A, Sarkis LM, Henwood T, Shun A, Gill AJ, et al. Risk of malignancy for each Bethesda class in pediatric thyroid nodules. J Pediatr Surg 2015;50:1147-9.

15. Siegel DA, King J, Tai E, Buchanan N, Ajani UA, Li J. Cancer incidence rates and trends among children and adolescents in the United States, 2001-2009. Pediatrics 2014;134:e94555.

16. Sklar C, Whitton J, Mertens A, Stovall M, Green D, Marina N, et al. Abnormalities of the thyroid in survivors of Hodgkin's disease: data from the Childhood Cancer Survivor Study. J Clin Endocrinol Metab 2000;85:3227-32.

17. Tucker MA, Jones PH, Boice JD Jr, Robison LL, Stone BJ, Stovall M, et al. Therapeutic radiation at a young age is linked to secondary thyroid cancer. The Late Effects Study Group. Cancer Res 1991;51:2885-8.

18. Sinnott B, Ron E, Schneider AB. Exposing the thyroid to radiation: a review of its current extent, risks, and implications. Endocr Rev 2010;31:756-73.

19. Williams ED, Doniach I, Bjarnason O, Michie W. Thyroid cancer in an iodide rich area: a histopathological study. Cancer 1977;39:215-22.

20. Czene K, Lichtenstein P, Hemminki K. Environmental and heritable causes of cancer among 9.6 million individuals in the Swedish Family-Cancer Database. Int J Cancer 2002;99:260-6.

21. Park YJ, Ahn HY, Choi HS, Kim KW, Park DJ, Cho BY. The long-term outcomes of the second generation of familial nonmedullary thyroid carcinoma are more aggressive than sporadic cases. Thyroid 2012;22:356-62.

22. Demidchik YE, Demidchik EP, Reiners C, Biko J, Mine M, Saenko VA, et al. Comprehensive clinical assessment of
740 cases of surgically treated thyroid cancer in children of Belarus. Ann Surg 2006;243:525-32.

23. Monaco SE, Pantanowitz L, Khalbuss WE, Benkovich VA, Ozolek J, Nikiforova MN, et al. Cytomorphological and molecular genetic findings in pediatric thyroid fine-needle aspiration. Cancer Cytopathol 2012;120:342-50.

24. Demidchik YE, Saenko VA, Yamashita S. Childhood thyroid cancer in Belarus, Russia, and Ukraine after Chernobyl and at present. Arq Bras Endocrinol Metabol 2007;51:748-62.

25. Gharib H, Papini E, Paschke R, Duick DS, Valcavi R, Hegedüs L, et al. American Association of Clinical Endocrinologists, Associazione Medici Endocrinologi, and European Thyroid Association Medical guidelines for clinical practice for the diagnosis and management of thyroid nodules: executive summary of recommendations. Endocr Pract 2010;16:468-75.

26. Haugen BR, Alexander EK, Bible KC, Doherty GM, Mandel SJ, Nikiforov YE, et al. 2015 American Thyroid Association Management Guidelines for Adult Patients with Thyroid Nodules and Differentiated Thyroid Cancer: The American Thyroid Association Guidelines Task Force on Thyroid Nodules and Differentiated Thyroid Cancer. Thyroid 2016;26:1-133.

27. Lyshchik A, Drozd V, Demidchik Y, Reiners C. Diagnosis of thyroid cancer in children: value of gray-scale and power doppler US. Radiology 2005;235:604-13.

28. Francis GL, Waguespack SG, Bauer AJ, Angelos P, Benvenga S, Cerutti JM, et al. Management guidelines for children with thyroid nodules and differentiated thyroid cancer. Thyroid.2015;25:716-59.

29. Leboulleux S, Girard E, Rose M, Travagli JP, Sabbah $\mathrm{N}$, Caillou B, et al. Ultrasound criteria of malignancy for cervical lymph nodes in patients followed up for differentiated thyroid cancer. J Clin Endocrinol Metab 2007;92:3590-4.

30. McLeod DS, Watters KF, Carpenter AD, Ladenson PW, Cooper DS, Ding EL. Thyrotropin and thyroid cancer diagnosis: a systematic review and dose-response metaanalysis. J Clin Endocrinol Metab 2012;97:2682-92. 